\title{
Social Skills Training for Abused Girls: Interpersonal Skills Training for Sexually Abused Girls
}

\author{
Mark D. Weist, Kathryn Vannatta, Kathleen K. Wayland \& Chianti Y. Jackson* \\ Duke University Medical Center, and University of Maryland School of Medicine*
}

\begin{abstract}
Four sexually abused girls participated in a 12-session group training program focused on improving interpersonal problems identified by the girls' teachers. Prior to and following the intervention, the girls underwent role-play assessment of their behaviour in relevant social situations with peers and teachers, and completed a self-report measures of perceived self-concept. For two of the girls, teachers completed checklists of their behavioural functioning before and after the intervention. On the role-play measure, the girls showed improvement on all of the trained behaviours (with peers and teachers), and evidenced behavioural improvements on untrained (generalisation) scenes. In addition, the girls reported improvements in perceived academic competence, peer functioning, appearance, and global self-concept following the training program. The study provides an example of a behavioural skills-training approach to address interpersonal deficits that may be shown by sexually abused children.
\end{abstract}

Interpersonal difficulties experienced by child victims of sexual abuse have been well documented. These include elevated levels of aggressive behaviour (Fatout, 1990), deficits in ageappropriate social skills (Vargo, Slavrakaki, Ellis, \& Williams, 1988), and increased fearful behaviour and withdrawal from others (Gelinas, 1983). In addition, sexually abused youth commonly evidence inappropriate sexual behaviour, confusion regarding their sexual self-concept, and feel stigmatised and "different" related to what they have been through. Such feelings may lead to avoidance of social relationships or "bartering" in interactions wherein the abused child feels she needs to give things to others in order to earn their favour (Finkelhor \& Browne, 1985). An additional issue that has not received much attention is that these children are at increased risk for taunting/teasing related to peer knowledge of the abuse.

While there have been a number of treatment programs that have attempted to improve the general and psychological adjustment of sexually abused children (e.g., Berman, 1990; Nelki \& Watters, 1989; Schact, Kerlinsky, \& Carlson,
1990; Sirles, Walsma, Lytle-Barnaby, \& Lander, 1988), few programs have explicitly targeted interpersonal problems of these children. One exception is a study by Lubell and Soong (1982), who provided group therapy to six early adolescents focusing on improving self-image, social skills, and peer relations. However, the investigators in this study did not use a structured, skillbuilding approach in training, and did not formally evaluate the program's effectiveness.

Kolko (1986) conducted a systematic social skills training program with an 11-year-old boy with a history of sexual abuse and neglect who had molested a neighbourhood girl. In a controlled single-subject design, the boy was trained to increase cognitive control over his behaviours and to improve social skills, with behavioural improvements documented on a role-play measure. Other examples of a systematic skill building approach to address the interpersonal problems of sexually abused children are lacking.

The purpose of the present study was to use a structured, behavioural approach to address interpersonal difficulties in four latency-age

We gratefully acknowledge the invaluable assistance provided by the staff of the Trauma Treatment Service of the Community Guidance Clinic, Durham, North Carolina.

Requests for reprints should be sent to Mark Weist, University of Maryland School of Medicine, Department of Psychiatry, 645 West Redwood Street, Baltimore, Maryland, 21201-1549; (410) 328-3522. 
sexually abused girls. We used a training model derived from social learning theory (Bandura, 1977) involving instructions, modelling, rehearsal, and feedback to improve social adjustment by their teachers (Wolf, 1978). To document the impact of our program, we used pre- and postmeasures of behavioural adjustment and self-concept completed by the girls and their teachers, and of social behaviour using a role-play measure of relevant social situations/skills.

\section{METHOD}

\section{Subjects}

Four girls (two pairs of sisters), aged 8 to 11 participated in the project. Initially, there were seven girls enrolled for the project; one attended only two sessions, and dropped out after the seventh session, and two sisters stopped coming to the group after the eighth session, reportedly related to time constraints imposed by their mother's new job. All the girls had been referred to the Trauma Treatment Service of the Community Guidance Clinic (CGC; Durham, North Carolina) by their parents or guardians for treatment of emotional/behavioural problems associated with sexual abuse and had previously received individual therapy. For each of the girls, there was between a 1- and 2-month hiatus in individual therapy efforts prior to their involvement in the group program. Parental consent to receive group therapy was obtained for each of the girls, as well as special consent for the girls to be videotaped. All data in the paper refer to the four girls who remained in the group training program throughout its duration. Background information for each of the girls was collected from their CGC therapist, and from their teacher in school.

"Jackie" (age 10.4) and "Jane" (age 8.3) were two caucasian sisters who lived with their single mother who was experiencing significant financial and personal difficulties. Jackie and Jane had both been sexually abused by their stepfather, who was no longer living in their home related to the abuse allegations. For both girls, the abuse involved fellatio, cunnilingus, and anal and vaginal intercourse. The two girls were vague about the time-frame and frequency of the abuse, but medical findings for both girls were consistent with "penetrating trauma of a chronic nature". Further, Jane had no gag reflex, which is consistent with the frequent performance of fellatio over an extended period of time.

In terms of interpersonal difficulties, Jackie reported to her CGC therapist that she felt alienated from and rejected by her classmates, and expressed her view that she needed to give them presents to obtain their friendship. She related that classmates frequently teased her about the abuse (e.g., asking for details, blaming her), did not pay attention to her, and excluded her from games. Jackie also expressed feeling reluctant to ask teachers for help related to a poor relationship that she had with a teacher in the prior academic year (this teacher was described as "unfriendly and unfair"). Jane's teacher reported that she was highly isolated from her classmates, who openly teased her about the abuse and academic limitations that she presented. Jane was also reported to be disruptive, to engage in attention-getting behaviours, and to display deficits in initiating interaction with classmates and teachers. She was reported to have particular problems in responding to corrective feedback from teachers about her behaviour and school performance.

"Monica" (age 8.8) and "Paula" (age 7.11) lived with a foster mother who presented as having some trouble managing their behaviour, and feeling stressed by financial problems. Both girls had been removed from the custody of their biological mother related to substantiated complaints of physical abuse and neglect. Monica and Paula had been sexually abused by a 16-year-old male cousin while they were in the custody of their mother. For both, the abuse involved digital and penile intercourse, and fellatio. The girls' report of the sexual abuse was inconsistent in terms of time frame and frequency and medical findings were "ambiguous."

Monica was reported to be subjected to a very high level of teasing and taunting from peers. Her teacher expressed her view that Monica was "really hurt" by this teasing, often reacting by "withdrawing and crying." She was also reported to have significant difficulty initiating interactions with both classmates and teachers, and was described as being unable to involve herself in group activities in an "age-appropriate" manner. Paula was also reported to receive considerable teasing from classmates, which she would often respond to with verbal and physical aggression. Further, she was described as engaging in high levels of classroom disruptiveness, "aggravating" other children, making up "fantasy like" stories, and having problems in recipro- 
cal social interaction (e.g., sharing, taking turns in games, conversing).

Review of recent (i.e., completed in 1990) psychological evaluations indicated that Jackie, Monica, and Paula were functioning in the normal range of intelligence, while Jane was functioning in the borderline range of intellectual ability (WISC-R Full Scale IQ score of 68).

\section{Measures}

The girls' teachers were requested to complete the Child Behaviour Checklist - Teacher Report Form (TRF; Achenbach, 1991) 2 weeks before, and 3 weeks after the group intervention. The TRF is a commonly used and psychometrically sound measure of child behaviour as perceived by teachers. It provides scores of internalising (e.g., depression, anxiety) and externalising (e.g., oppositionality, aggressiveness) behaviour problems, as well as teacher Likert ratings of classroom behaviour.

The girls completed the Perceived Competence Scale for Children (PCSC; Harter, 1982) 1 week prior to, and 1 week following the group. The PCSC provides an assessment of children's global self-concept, and self-perception of functioning in academic, peer relations, athletic, appearance, and behavioural domains. The PCSC is reported to have excellent reliability (test-retest and internal consistency) and construct validity.

\section{Role-Play Test}

The role-play test was developed to allow measurement of identified behaviours of concern. The measure contained 10 scenes falling in six behavioural domains: (a) initiating and maintaining positive interactions with peers, (b) responding to positive social gestures from peers, (c) ignoring peer taunting or provocation, (d) assertive behaviour, (e) asking teachers for help, and (f) responding appropriately to corrective feedback from teachers. These behavioural domains corresponded to social difficulties presented by the four girls. Role-play scenes were chosen for inclusion in the measure based on review of a larger list of scenes by four agency therapists, who rated the scenes on relevance to social difficulties of sexually abused children. Six of the scenes were used in training sessions and for pre- and postassessment. Four of the scenes were used only in assessment sessions to enable measurement of behavioural generalisation from trained to untrained situations (Stokes
\& Baer, 1977). Six of the scenes (four training, two generalisation) involved peer interaction, and four of the scenes (two training, two generalisation) involved interaction with teachers. The role-play test is presented in Table 1.

The girls were assessed on the role-play test 1 week before the intervention, and following the last group session. The investigator provided background narration, a prompter then provided a cue line, the child responded, and the prompters then provided standard follow-up responses to make the role-play interaction seem more realistic (Curran, 1978). Three prompters were used, a female college student (who attempted to dress and act in a childlike manner) for scenes involving peer interaction, and one male and one female agency therapist for scenes involving teacher interaction. All three prompters were trained on, and practiced, the role-play procedure before assessment. Prior to actual assessment, the girls practised two scenes. Throughout the role plays, they were encouraged to respond as if the situation was actually happening.

\section{Procedures}

Prior to the commencement of the group, the girls completed premeasures and underwent role-play assessment, and teachers were contacted to provide their observations of the girls' social behaviour in school. Teachers responded to open-ended questions on each child's social behaviour in various situations (e.g., "How does get along with her classmates during recess?"), identified particular problem areas, and rated the child on various dimensions of social interactions with adults and peers (e.g., "responds to corrective feedback," "participates in group activities") on 7-point Likert scales (with $1=$ very unskilled, and $7=$ very skilled). Based on this input from teachers, and from the girls' guardians (obtained during intake evaluations) skill deficits that were common to the girls were identified (see behavioural domains of the role-play test).

\section{Intervention}

The intervention was conducted at the Community Guidance Clinic, where each of the girls had previously received individual therapy. Following the completion of premeasures, one group session was held during which the children were introduced to the group, the leaders (the two senior investigators) and each other, 


\section{PEER SCENES}

1) Initiating interaction

T. There's a new girl in your class who's sitting by herself. She seems like a nice girl and you would like to be her friend. You go up to her and say:

2) Responding to positive initiations.

T. After school, a girl who you think is really nice says to you: "I really liked the picture you made in art class today." (It's really nice.")

3) G. On your way to lunch, you see a friend of yours who says: "Hey, I really like your dress!" ("It's really pretty.")

4) Responding to provocation

T. At lunch, a girl who you don't like looks at you and says: "Why did you fix your hair that way. It really looks stupid!" ("It really looks silly")

5) G. You can't work out a math problem on the board at school. "I can't believe you didn't get it. That problem is so easy!" ("I know how to do all the problems")

6) Assertion.

T. A girl in your class borrowed your bookbag three weeks ago. She said she was only going to borrow it for one day. You would really like to have your bookbag back. You see her in the library and she says: "Do you mind if I keep your bookbag until next week?" ("Just one more week?!”)

\section{TEACHER SCENES}

7) Asking for help.

T. You're falling behind in your assignments in Science class and you're worried that you're going to get a bad grade. After class, you go in to see your teacher, Ms. Morris to talk to her about this problem. You say:

8) G. You sit in the back of class in English and you're having a hard time hearing the teacher due to other kids goofing off. You're worried that you're going to fall behind. After class, you go up to your teacher, Ms. Jones and say:

9) Responding to corrective feedback.

T. You haven't been getting your homework done in Social Studies because of problems you're having at home. Your teacher, Mr. Hayes says: "I'm very disappointed that you have fallen so far behind in your assignments, and if this doesn't change, you're going to get a poor grade in my class. What's been going on?" ("It's important to get our assignments completed on time.")

10)G. You're not understanding how to work out the problems in your math class. Your teacher, Mr. Smith asks to see you after class and says: "You're getting a lot of answers wrong on your assignments and on tests. What's been happening?" ("Well, just try to do better.")

Note: $\mathrm{T}=$ Training scene, $\mathrm{G}=$ Generalisation scene; Follow-up comments by the role-play prompters are presented in parentheses.

and relationship building exercises followed. Behavioural skills were then taught to the girls in a sequential and cumulative fashion (i.e., each training session included review of previously trained behaviours). Training in each behavioural domain of the role-play test was conducted, and in addition, the girls were trained in molecular social skills (e.g., eye con- tact, speech duration) when these were determined to be deficient. Definitions of trained behaviours are presented in Table 2 .

Upon introduction of training for each behaviour, the leaders defined the behaviour, discussed its importance to peer or teacher relations, and encouraged the girls to talk about their own observations of good and poor exam- 
TABLE 2 Behavioural Definitions of Targeted Behaviours

1 a) Initiates interaction. Greets, asks questions, or compliments the role-play partner in an enthused/interested manner.

b) Maintains interaction. Responds to partner's comments; initiates questions, statements to maintain conversation with partner.

2) Responds to positive initiations. Responds to positive initiations from partner in an attentive and interested manner.

3) Responds to provocation. Ignores provocative comments from partner; does not look at partner; appears unaffected.

4) Assertive behaviour. Denies partner's unreasonable requests in a firm, but polite and respectful manner.

5) Asking teachers for help. Expresses to adult role-play partner need for help, and requests assistance in a polite fashion.

6) Responds to corrective feedback. Appears attentive and interested in teacher comments; does not display angry or disrespectful behaviours.

7) Eye contact. Maintains eye contact, without staring while listening to and speaking to the roleplay partner.

8) Voice quality. Speaks to the partner after a minimal latency, in a moderately loud tone, without notable speech dysfluencies.

9) Body orientation. Good posture; orients body to partner.

ples of the behaviour. The leaders then modelled the behaviour, and the girls took turns role playing and providing feedback to each other using training scenes from the role-play test. The leaders also provided feedback and encouraged the same from the girls. This process continued until each of the girls had mastered the targeted behaviour. The training format of instruction, demonstration, rehearsal, and feedback is based on social learning principles to maximise children's learning of behavioural skills, and has been used in numerous group skill-training programs for children (e.g., Bornstein, Bellack, \& Hersen, 1977; Weist, Borden, Finney, \& Ollendick, 1991).

Twelve group training sessions were conducted. Following the initial introductory session, the following training sequence occurred: Two sessions were focused on initiating and maintaining interaction, one session was focused on responding to positive initiations, two sessions were centred around responding to provocation, two sessions were focused on assertion, one session was centred around asking teachers for help, one session was focused on responding to corrective feedback, and two sessions were spent in review of trained behaviours, and preparing the girls for the termination of the group. Training on foundational social skills of eye contact, voice quality (e.g., loudness, duration of speech), and body orientation (e.g., pos- ture, positioning of their bodies in relation to the interpersonal partner) occurred throughout the group sessions when behavioural deficits were observed. Thus, the girls were trained on a total of nine behaviours. Following the completion of training, the girls underwent individual postassessment (role-play assessment and completion of the PCSC), and then participated in a termination pizza party.

Within 2 weeks of the termination of the group, teachers were requested to complete post, the Child Behaviour Checklist, TRF (Achenbach, 1991). Teachers were not informed that the girls had participated in a group training program.

\section{Behavioural Observation}

After the termination of the group, the girls' videotaped role-plays were observed to evaluate behavioural changes from pre- to postintervention. An independent undergraduate research assistant was recruited to view and score the tapes as the primary observer; the senior investigator also viewed all tapes, serving as the reliability observer. The primary observer was kept naive as to the purposes of the study, and was given no information on the sequence of roleplay assessments. All tapes were reviewed by both observers to ensure an adequate sample to determine interobserver agreement for each behaviour. Prior to actual observation, 
behavioural definitions were extensively reviewed. The observers then viewed the tapes independently, observing them one at a time, and stopping the tapes following each scene to provide behavioural ratings. Each of the nine behaviours presented in Table 2 were rated on 7-point Likert scales with 1 representing the absence of the behaviour, and 7 representing $a$ very high level of the behaviour. For two roleplay scenes (generalisation scenes 3 and 5) from the first role-play assessment (Jackie's preassessment), the observers conferred after completing independent behavioural ratings to ensure consistency in rating procedures, and to discuss subtle differences in the girls' behaviours. Ratings from these scenes were not included in the final scoring.

Thereafter, the tapes were reviewed without discussion by the observers. Pearson productmoment correlations were then computed for the ratings of the two observers. These correlations, and associated probability values were as follows: initiates interaction $=.87(p=.004)$, responds to positives $=.83(p=.0001)$, ignores provocation $=.94(p=.001)$, assertive behaviour $=.98(p=.001)$, asks for help $=.88$ $(p=.0001)$, responds to corrective feedback $=$ $.94(p=.0001)$, eye contact $=.76(p=.006)$, voice quality $=.88(p=.001)$, and body orienta- tion $=.88(p=.0001)$. Thus, all nine behaviours were observed reliably.

\section{RESULTS}

Table 3 presents means of the trained behaviours for the performances of the four girls before and following the intervention. As shown in the table, improvement was evidenced for all nine behaviours. There was also improvement noted for behaviours displayed on all four of the untrained (generalisation) scenes. In general, such improvements either matched the level of improvement on trained scenes, or was slightly lower. Inspection of means for each of the girls revealed consistent improvements, with only occasional exceptions to this pattern (e.g., Jackie and Jane did not show improvements on the behaviour of "responding to positives"; Jackie did not evidence improvements in her voice quality).

Child Behaviour Checklist, Teacher Report Forms (Achenbach, 1991) from before and following the intervention were received from only two of the girls' teachers (Jane and Monica). From pre- to posttraining, Jane's teacher rated her as working harder in class, and behaving more appropriately. Jane was reported to have decreased externalising behaviour problems

TABLE 3 Means on Trained Behaviours Pre- and Postintervention

\begin{tabular}{lcc}
\hline Behaviour & Pre-Mean & Post-Mean \\
\hline Initiating Interaction & 3.5 & 5.5 \\
Responding to Positives & & \\
Training Scene & 4.0 & 5.0 \\
${ }^{*}$ Generalisation Scene & 4.0 & 5.0 \\
Ignoring Provocation & & \\
Training Scene & 3.0 & 6.7 \\
${ }^{*}$ Generalisation Scene & 2.5 & 4.0 \\
Assertion & 1.3 & 5.5 \\
Asking for Help & & \\
Training Scene & 4.0 & 6.5 \\
Generalisation Scene & 4.0 & 4.7 \\
Responding to Feedback & & \\
Training Scene & 3.0 & 4.7 \\
Generalisation Scene & 3.7 & 5.4 \\
Eye Contact & 4.4 & 5.5 \\
Voice Quality & 3.4 & 4.4 \\
Body Orientation & 1.2 & 3.6 \\
\hline
\end{tabular}

Note: Means represent the average Likert rating ( 1 to 7 , with 7 being best) for each behaviour for the four girls. ${ }^{*}=$ average computed for ratings for three of the four girls. 
(e.g., aggression, noncompliance), with her $T$ score in this area decreasing from 76 (above the clinical cut-off) to 63 (below the clinical cutoff). Jane's teacher did not report changes in the level of her internalising behaviours (e.g., depression, anxiety); however, these scores were within the normal rarge at both points in time ( $T$ scores around 50 ). There were no changes in teacher ratings of Monica's classroom behaviour from pre- to postintervention. Similarly, Monica's scores in externalising and internalising behavioural realms did not appreciably change from pre- to postassessment ( $T$ scores around 50 for internalising behaviours, and around 65 for externalising behaviours).

Scores for Jackie, Paula, and Monica on the Perceived Competence Scale for Children (PCSC; Harter, 1982) were obtained both before and following the group training program. Jane had difficulty understanding self-report measures, so these were not collected from her. Total scores for the three other girls on each of the assessment realms of the PCSC are present- ed in Table 4. As presented in the Table, all three girls evidenced improvement in global self-concept. Further, each of the girls indicated perceptions of enhanced competence in academics, peer relations, and appearance. Jackie and Monica did not show improvements on subscales measuring perceived behavioural functioning, and athletic competence (which would not be expected to change from participation in the training program). All three girls showed an improved overall mean score (computed for the six subscales).

\section{DISCUSSION}

In this study, four girls participated in a group training program to address social difficulties identified by their teachers. Following the intervention, the girls showed improvements in social behaviour on a role-play test, and reported enhanced self-concept. Anecdotally, the children appeared to enjoy the group training sessions, which were nonthreatening to them given the focus on acquiring social skills versus dis-

TABLE 4 Scores on the PCSC Pre- and Postintervention

\begin{tabular}{|c|c|c|c|}
\hline & Domain & Prescore & Postscore \\
\hline \multirow[t]{7}{*}{ Jackie } & Global Self-Concept & 13 & 21 \\
\hline & Academic Competence & 14 & 18 \\
\hline & Peer Relations & 11 & 15 \\
\hline & Appearance & 16 & 23 \\
\hline & Behavioural Functioning & 14 & 6 \\
\hline & Athletic Competence & 12 & 19 \\
\hline & Overall Mean & 13 & 17 \\
\hline \multirow[t]{7}{*}{ Paula } & Global Self-Concept & 15 & 23 \\
\hline & Academic Competence & 16 & 21 \\
\hline & Peer Relations & 19 & 24 \\
\hline & Appearance & 19 & 24 \\
\hline & Behavioural Functioning & 15 & 23 \\
\hline & Athletic Competence & 20 & 24 \\
\hline & Overall Mean & 17 & 23 \\
\hline \multirow[t]{7}{*}{ Monica } & Global Self-Concept & 18 & 24 \\
\hline & Academic Competence & 21 & 24 \\
\hline & Peer Relations & 6 & 10 \\
\hline & Appearance & 12 & 24 \\
\hline & Behavioural Functioning & 22 & 24 \\
\hline & Athletic Competence & 24 & 24 \\
\hline & Overall Mean & 17 & 22 \\
\hline
\end{tabular}


cussion of feelings related to past trauma. Further, the active use of role-play served to keep the children stimulated and interested in the group, and also facilitated lively and humorous interchange among the girls and the group leaders. Experts on treating traumatised children have emphasised the need for multifaceted intervention programs to address the emotional and behavioural sequelae of the abuse (Finkelhor, 1986; Wolfe \& Wolfe, 1988). As such, the use of skills-training groups may represent an important method of augmenting emotionfocused individual therapy efforts with sexually abused children.

The present study represents the relatively novel application of social learning principles for behavioural skill training with sexually abused children. Our literature review revealed only one study that used a systematic behavioural approach to addressing social deficits related to sexual abuse; Kolko (1986) used such an approach to train social cognitive and behavioural skills to a sexually abused boy. We provided structured behavioural training to four sexually abused girls using a format of instructions, modelling, rehearsal, and feedback that has been reported to increase children's learning and retention of skills (Bandura, 1977). Further, the provision of this training in a group format enabled the girls to observe and model behavioural skills in each other, as well as providing each other with feedback and encouragement on skill acquisition.

We used a social validation strategy (Wolf, 1978) of polling the girls' teachers to identify behavioural targets for group training. Social validation of behavioural targets is a critically important step to ensure that interventions are focused on meaningful behaviours that are associated with desired treatment outcomes (Weist, Ollendick, \& Finney, 1991). Our participating girls were trained to initiate interaction, respond to positive social gestures, ignore teasing and taunting, and assertively refuse unreasonable requests from peers. They were trained to ask for help, and respond appropriately to corrective feedback from teachers. Each of these behaviours was rated as important for effective social interaction at school by the girls' teachers, and before training the girls exhibited these behaviours at generally low levels (with some exceptions). We also targeted molecular social skills of eye contact, voice quality, and body orientation, which have been found in other studies to be associated with positive social adjustment in children (Weist \& Ollendick, 1991).

As shown in their role-play performances following the group intervention, the girls learned the trained skills, and these skills generalised to untrained role-play scenes. Although we were pleased to see this generalisation in skills, we acknowledge that we did not assess behavioural changes for the girls in their social environments. As such, we do not know if they showed actual improvements in their social behaviours at school or with family and friends. Unfortunately, we only received pre- and postbehavioural checklists from two of the girls' teachers. While one of the girls (Jane) was rated as showing less externalising behaviours (e.g., aggression, noncompliance) following the intervention, no behavioural changes were reported for the other girl (Monica). Our efforts to acquire ratings by teachers of the girls' classroom social behaviours following the intervention were similarly unsuccessful.

We were very pleased that each of the three girls completing self-report measures reported improvements in their global self-concept, and perceptions of academic competence, peer relations and appearance following the training program. Admittedly, due to our very small sample, and the lack of a control group, we cannot assuredly conclude that these improvements in self-perception were associated with the group training program.

Finally, we did not collect follow-up data in the present study. The group terminated in the Spring, and our efforts to recruit the girls for follow-up the following Fall were fruitless. Therefore, we are unsure if the behavioural gains and improvements in self-concept evidenced by the girls following the training program maintained across time. Despite this and other limitations of our study (e.g., small sample size, absence of a control group), we have provided an example of a structured behavioural skills-training approach to address social deficits in sexually abused children. Future research focused on assessing social problems in traumatised children, and providing controlled group interventions with assessment of treatment gains in the children's natural environments, and maintenance of these gains over time is needed. 


\section{REFERENCES}

Achenbach, T.M. (1991). Manual for the Teacher Report Form. Burlington, VT: University of Vermont Department of Psychiatry.

Bandura, M. (1977). Social learning theory. Englewood Cliffs, NJ: Prentice-Hall.

Berman, P. (1990). Group therapy techniques for sexually abused preteen girls. Child Welfare, 69, 239-252.

Bornstein, M., Bellack, A., \& Hersen, M. (1977). Social skills training for unassertive children: A multiple baseline analysis. Journal of Applied Behaviour Analysis, 5 , 443-454.

Curran, J.P. (1978). Comments on Bellack, Herse, and Turner's paper on the validity of role-play tests. Behaviour Therapy, 9, 462-468.

Fatout, M.F. (1990). Aggression: A characteristic of physically abused latency-age children. Child and Adolescent Social Work Journal, 7, 365-376.

Finkelhor, D. (1986). A source book on child sexual abuse. Beverly Hills, CA: Sage.

Finkelhor, D., \& Brown, A. (1985). The traumatic impact of child sexual abuse: A conceptualization. American Journal of Orthopsychiatry, 55, 530-541.

Gelinas, D.J. (1983). The persisting negative effects of incest. Psychiatry, 46, 312-332.

Harter, S. (1982). The Perceived Competence Scale for Children. Child Development, 53, 87-97.

Kolko, D.J. (1986). Social-cognitive skills training with a sexually abused and abusive child psychiatric inpatient: Training, generalisation and follow-up. Journal of Family Violence, 1, 149-165.

Lubell, D., \& Soong, W. (1982). Group therapy with sexually abused adolescents. Canadian Journal of Psychiatry, 27, 311-315.
Nelki, J.S., \& Watters, J. (1989). A group for sexually abused young children: Unravelling the web. Child Abuse and Neglect, 13, 369-377.

Schact, A.J., Kerlinsky, D., \& Carlson, C. (1990). Group therapy with sexually abused boys: Leadership, projective identification, and countertransference issues. International Journal of Group Psychotherapy, 40, 401-417.

Sirles, E.A., Walsma, J,, Lytle-Barnaby, R., \& Lander, L.C. (1988). Group therapy techniques for work with child sexual abuse victims. Social Work with Groups, 11, 67-78.

Stokes, T.F., \& Baer, D.M. (1977). An implicit technology of generalisation. Journal of Applied Behaviour Analysis, 10, 349-367.

Vargo, B., Slavrakaki, C., Ellis, J., \& Williams, E. (1988). Child sexual abuse: Its impact and treatment. Canadian Journal of Psychiatry, 33, 468-473.

Weist, M.D., Borden, M.C., Finney, J.W., \& Ollendick, T.H. (1991). Social skills for children: Training empirically derived target behaviours. Behaviour Change, 8 , 174-182.

Weist, M.D., \& Ollendick, T.H. (1991). Toward empirically valid target selection with children: The case of assertiveness. Behaviour Modification, 15, 213-227.

Weist, M.D., Ollendick, T.H., \& Finney, J.W. (1991). Toward the empirical validation of treatment targets in children. Clinical Psychology Review, 11, 515-538.

Wolf, M.M. (1978). Social validity: The case for subjective measurement or how applied behaviour analysis is finding its heart. Journal of Applied Behaviour Analysis, 11, 203-214.

Wolfe, V., \& Wolfe, D. (1988). The sexually abused child. In E.J. Mash \& L.G. Terdal (Eds.), Behavioral assessment of childhood disorders (2nd ed., pp. 670-714). New York: Guilford. 